\title{
Contemporary possibilities in the diagnostics of anterior and posterior eye diseases with the use of new-generation OCT
}

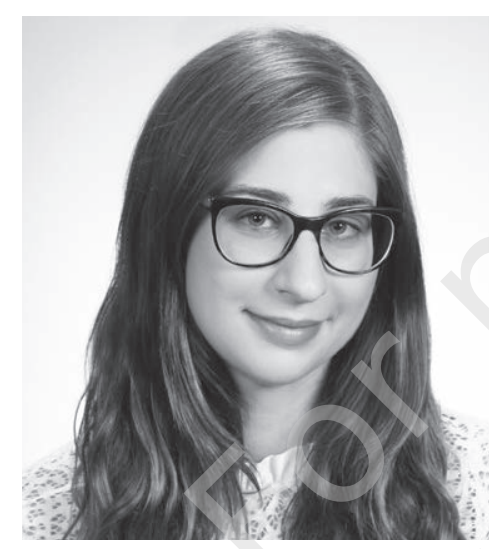

H I G H LI GHTS

Optical coherence tomography is an indispensable tool in diagnostics and observation of many eye diseases. The use of Solix FullRange ${ }^{\text {TM }}$ OCT\&OCTA apparatus provides more accurate examination of the anterior and posterior segments of the eye.

\section{Katarzyna Paczwa' ${ }^{1}$ Justyna Mędrzycka' , Joanna Gołębiewska ${ }^{1,2}$, Radosław Różycki ${ }^{1}$}

'Ophthalmology Clinic, Military Institute of Aviation Medicine, Warsaw, Poland Head: Radosław Różycki, MD, PhD

${ }^{2}$ Faculty of Medicine, Lazarski University, Warsaw Dean: dr hab. n. med. Paweł Olszewski

\section{ABSTRACT}

Optical coherence tomography is a non-contact imaging method of the anterior and posterior segments of the eye that is based on laser scanning in spectral domain. This study presents diagnostic possibilities of the new generation Solix FullRange ${ }^{\mathrm{m}}$ OCT\&OCTA apparatus (Optovue) to examine meibomian glands, cornea, anterior chamber, as well iridocorneal angles and lens. In the posterior segment of the eye it allows for the precise evaluation of the vitreous body, choroid, retina, optic nerve and blood-flow measurements.

Key words: OCT, angio-OCT 


\section{INTRODUCTION}

Optical coherence tomography (OCT) is a non-invasive, non-contact and repeatable imaging method that is based on optical scanning [1]. It provides detailed images of retina, choroid, optic nerve, and anterior segment of the eye. This method has become an indispensable tool in diagnostics and observation of many eye diseases.

When in vivo retinal section was obtained for the first time in 1991, a constant strive to obtain images of the highest possible quality began $[1,2]$. Currently, there are many different models of equipment available on the market, offering increasingly higher quality of examination.

The OCT devices provide real-time histology-compatible tissue cross-sections and three-dimensional imaging of anterior and posterior segment structures of the eyeball. The instruments have an integrated database. It allows for quantitative comparison of measurements of a specific patient with a database of healthy subjects, facilitating diagnostics of eye diseases. Moreover, they allow for the comparison of subsequent examinations performed on a patient in order to monitor treatment and disease progression.

The OCT examination provides the assessment of both anterior and posterior segment of the eye.

\section{ANTERIOR SEGMENT OCT}

In an anterior segment examination using a Solix FullRange ${ }^{\circledast}$ OCT\&OCTA apparatus, with two external lenses
$(10 \mathrm{~mm}, 18 \mathrm{~mm})$, the exact structure of the histological layers of the cornea, including the tear film may be assessed, as well as the measurement of the thickness - pachymetry in 16 meridians, the lacrimal point and an accurate assessment of the structure of the anterior chamber (fig. 1, 2). Furthermore the full range $18 \times 6.25$-mm lens allows for the imaging of the anterior chamber angles. Anterior segment optimal coherence tomography (AS-OCT) is also used to measure the thickness of the lens and to assess the cataract severity. New imaging systems enable the use of this non-invasive procedure to diagnose and monitor corneal diseases, such as keratopathy and keratoconus, additionally in cases of qualification for laser vision correction, dry eye syndrome, or glaucoma [3].

\section{POSTERIOR SEGMENT OCT}

The OCT of the posterior segment of the eye allows for evaluation of the choroid, retina, retinal nerve fiber layer (RNFL), ganglion cell complex (GCC), and optic nerve disc. Optovue has introduced a retinal and vitreous imaging system with 6.25 -mm deep scans, that is adapted to patients with high myopia. Moreover, the Solix system provides an accurate assessment of the vitreous body, its structure, and the adhesion of the premacular bursa and Cloquet's canal to the retina (premacular bursa, Cloquet's canal) (fig. 3).
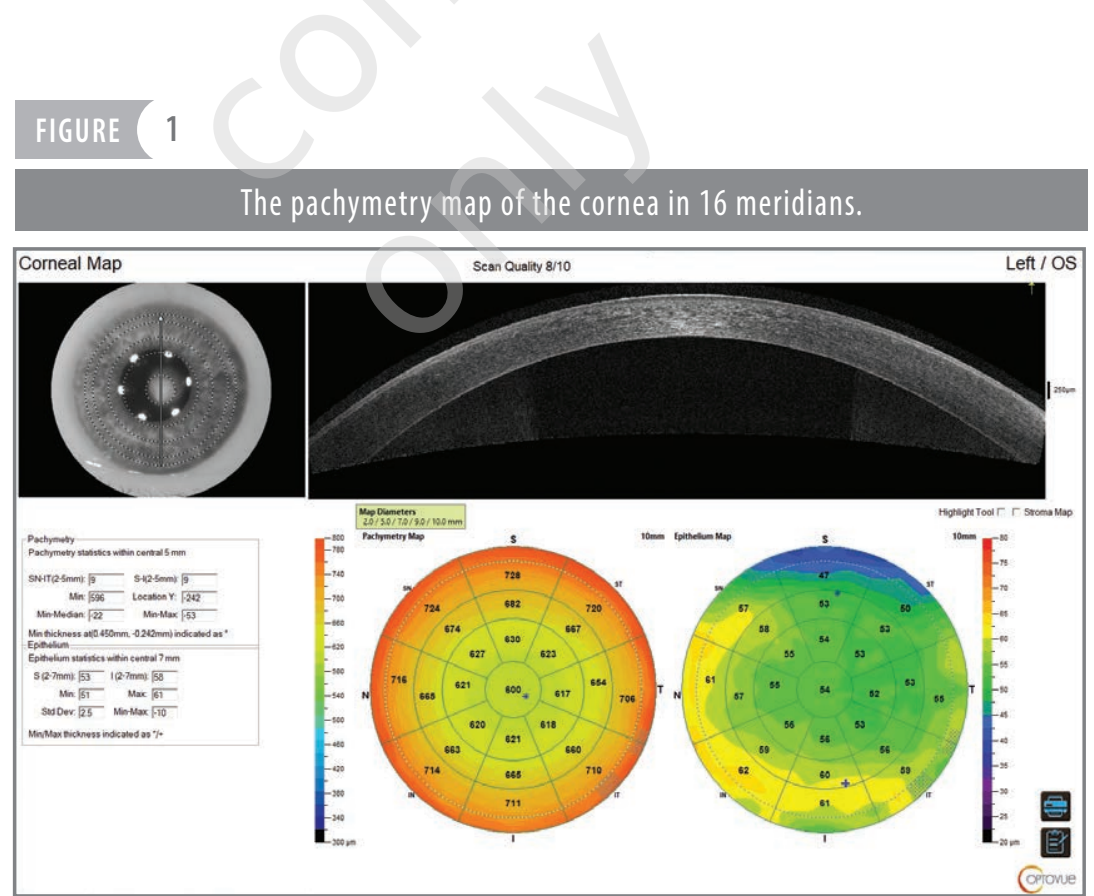


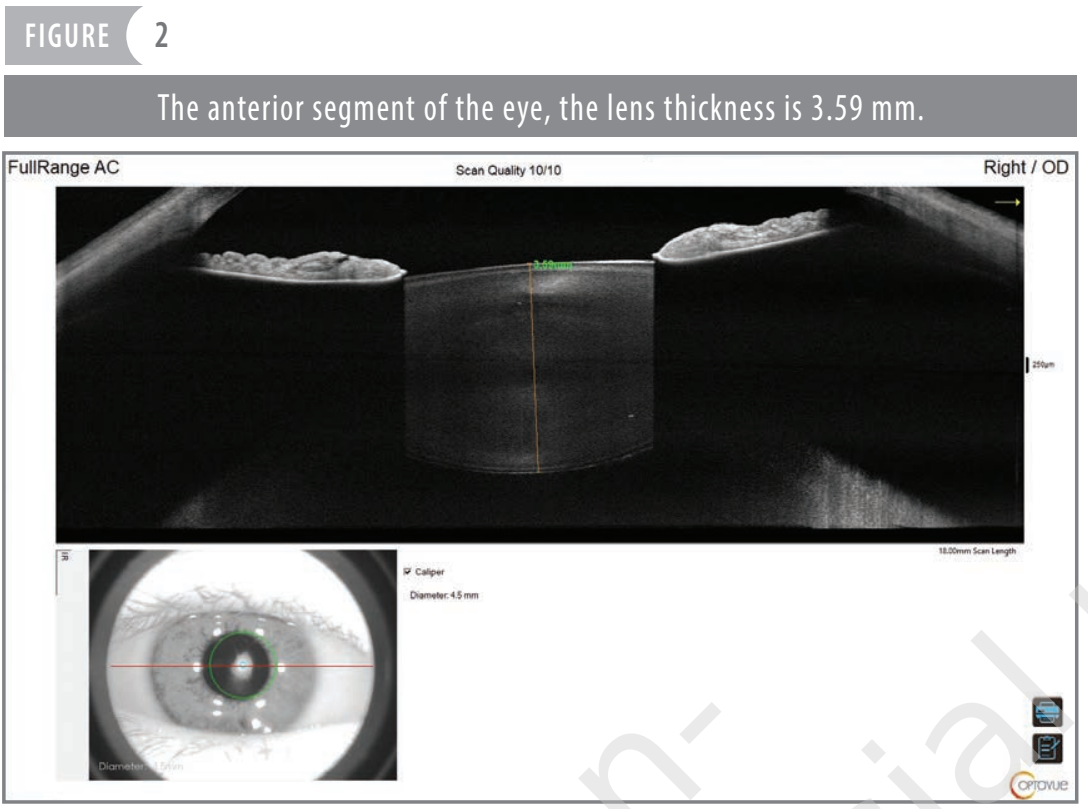

\section{FIGURE 3}

OCT-B-scan in a patient with diabetic retinopathy and vitreopathy shows abnormalities in retinal layers, atrophy of the retinal pigment epithelium in the temporal part of the macula (after laser photocoagulation) and vitreoschisis.

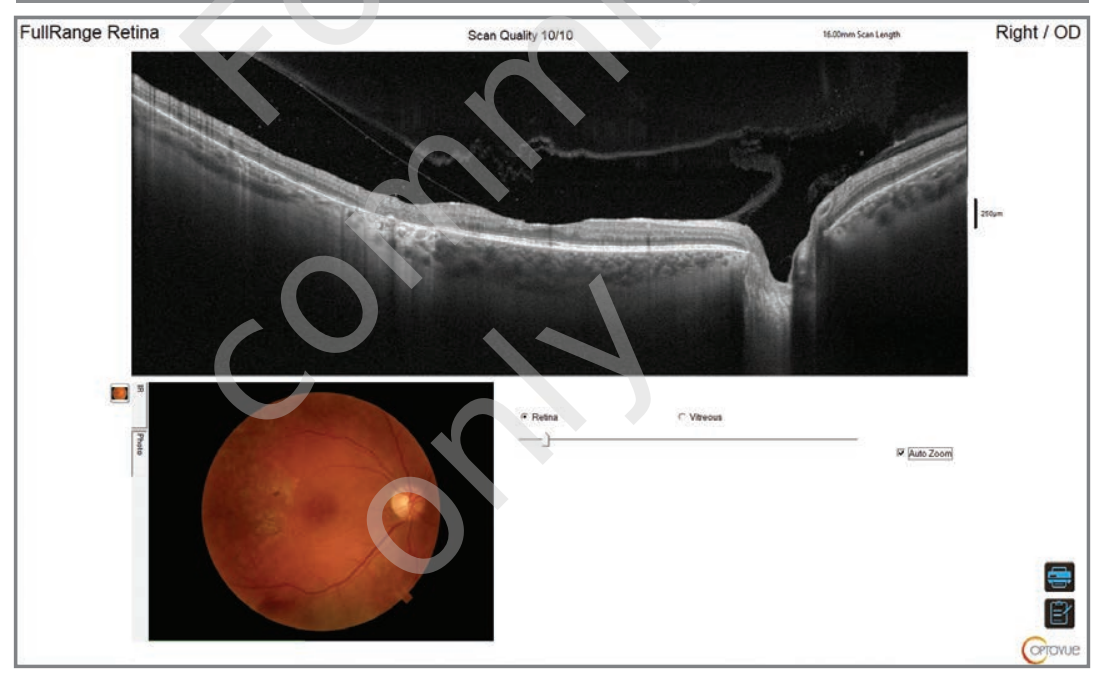

\section{ANGI0-OCT}

The OCT does not; however, allow for the assessment of microvascular function in the retina. To do this, the AngioVue ${ }^{\oplus}$ imaging system has been developed - it provides visualization of the blood flow, based on intrinsic motion contrast, therefore, unlike fluorescein angiography (FA), it does not require contrast administration $[2,4,5]$. AngioAnalytics software maps and measures vascular density, non-flow areas to identify ischemic areas, and vessel surface area to assess neovascularization [6]. The angio-OCT examination is one of the best tools for imaging and measuring capillary decline, and abnormal vessels in retinal diseases, glaucoma, and other optic nerve neuropathies (fig. 4) [7-9]. 
Angio-0CT picture in patient with diabetic retinopathy, map of the vessel density in superficial retinal capillary plexus shows capillary non-flow areas in temporal part of the macula.

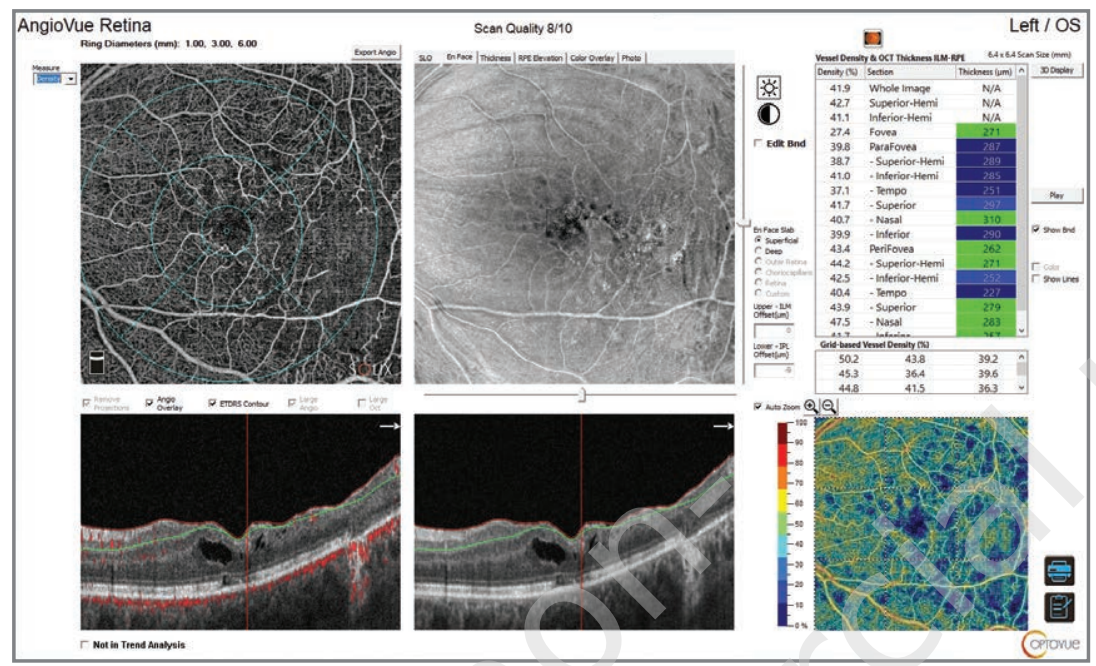

The device performs 120,000 A-scans per second, thus producing high quality images of the retina, choroid and vitreous body. The $12 \times 12 \mathrm{~mm}$ scans help detect lesions in the peripheral areas of the retina. AngioMontage ${ }^{\mathrm{rm}}$ combines images of the macula and optic nerve disc to produce $16 \times 9$-mm or $16 \times 16$-mm high-density broadband visualization. This image of the microvasculature enables evaluation of a significant part of the retina (fig. 5).
AngioVue Disc provides simultaneous examination of the nerve fiber layer, three-dimensional scanning of the optic nerve disc, measurement of the retinal ganglion cell complex, and assessment of radial peripapillary capillary flow density. The ability to quickly scan and simultaneously perform OCT and angio-OCT examinations and to generate a report that may be compared to the database provides the most accurate examination in the early stages of glaucoma before other symptoms appear [10].

\section{FIGURE ( 5}

The analysis of the macular and optic nerve disc perfusion using AngioMontage.

A. Normal flow in the posterior pole of the left eye. B. Branch retinal vein occlusion

of the inferior branch vein in the right eye. It shows non-perfusion areas of inferior

and temporal part of the macula, capillary anastomoses and neovascularization near inferior temporal vessel.

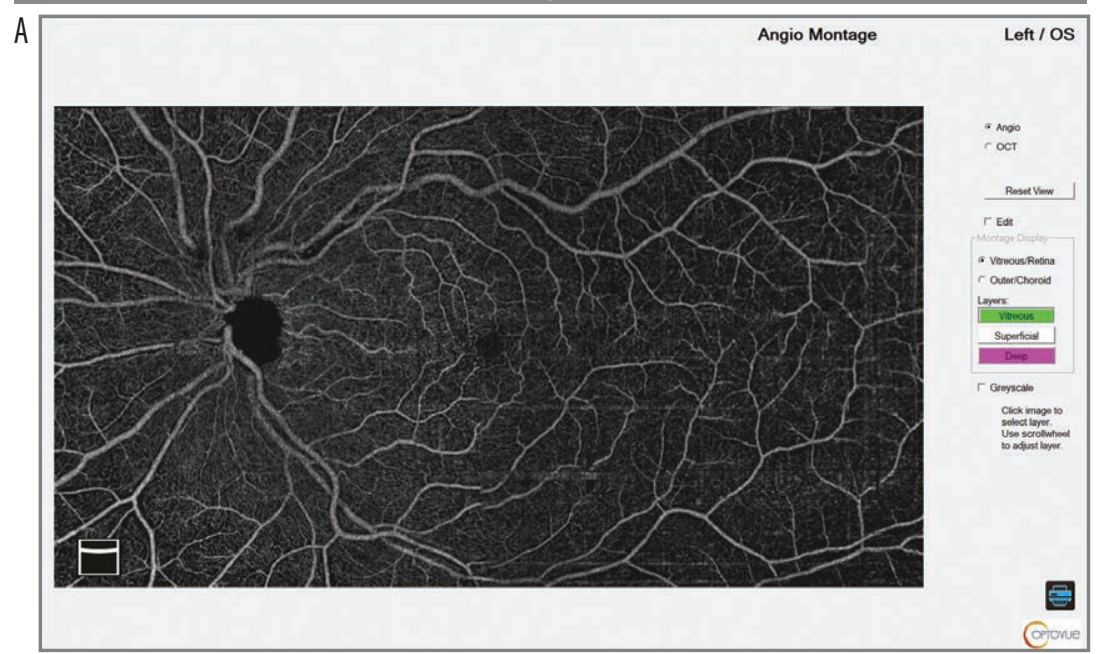




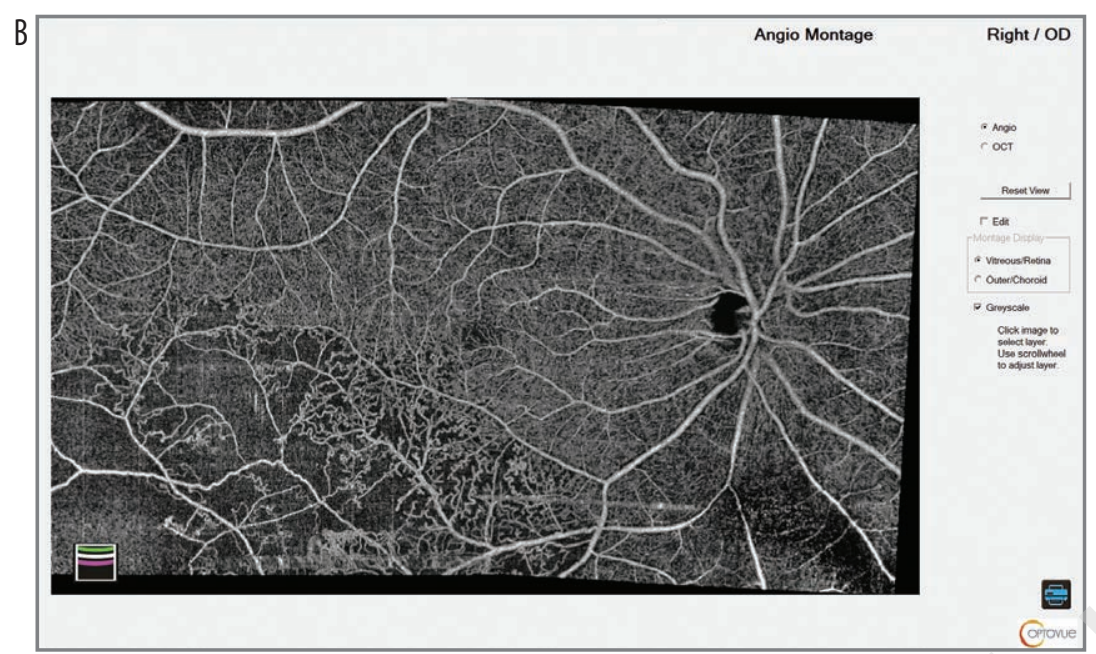

\section{ADDITIONAL POSSIBILITIES}

Moreover, the device offers to take pictures of the anterior segment of the eye, including the protective apparatus. It is possible to evaluate the eyelids, Meibomia glands, conjunctivae, and the iris (fig. 6). This allows for photographic documentation and monitoring of the progression of eyelid diseases, dry eye syndrome, red eye conditions and iris abnormalities. and angio-OCT, Solix FullRange ${ }^{\mathrm{TM}}$ OCT\&OCTA offers the most advanced spectral OCT on the market. It allows for obtaining the widest and deepest images of the retina, choroid and vitreous body, adapted to patients with high myopia, and getting the widest scans in angio-OCT. Additionally, this device can scan the etnire anterior segment of the eye and perform a number of tests to monitor and diagnose glaucoma.

Figures: from the author's own materials.

\section{FIGURE 6}

\section{The photography of the anterior segment of the eye showing Meibom's glands.}

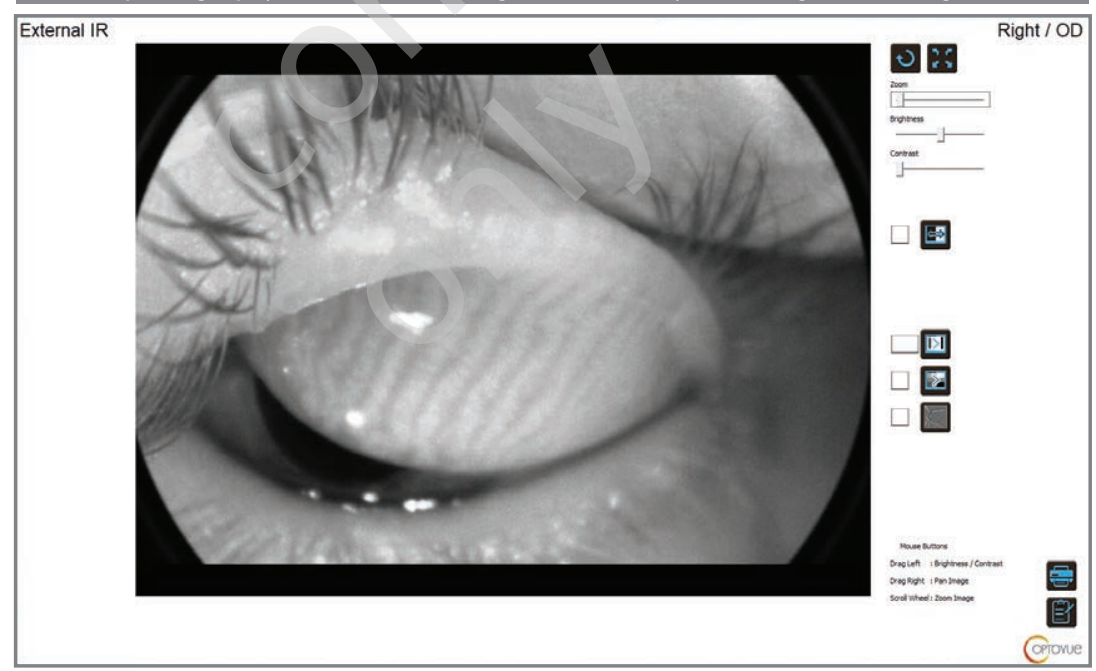

\section{CONCLUSIONS}

Progress and improvement of the anterior and posterior segment imaging are continuous. New equipment appears constantly on the market, offering increasingly more precise examinations. Due to integrated fundus camera, possibility of external photography, Meibomian gland module 


\section{CORRESPONDENCE}

\section{Katarzyna Paczwa}

Ophthalmology Clinic,

Military Institute of Aviation Medicine

01-755 Warsaw, Zygmunta Krasińskiego 54/56

e-mail: kasiapaczwa@gmail.com

\section{ORCID}

Katarzyna Paczwa - ID - https://orcid.org/0000-0003-3825-3727 Justyna Mędrzycka - ID - https://orcid.org/0000-0001-9578-719X Joanna Gołębiewska - ID - https://orcid.org/0000-0002-3013-4363 Radosław Różycki - ID - http://orcid.org/0000-0001-7040-026X

\section{References}

1. Huang D, Swanson EA, Lin CP et al. Optical coherence tomography. Science. 1991; 254(5035): 1178-81. http://doi.org/10.1126/science.1957169.

2. Hautz W, Gołębiewska J (ed). OCT i Angio-OCT w schorzeniach tylnego odcinka gałki ocznej. Medipage, Warszawa 2015.

3. Ang M, Baskaran M, Werkmeister RM et al. Anterior segment optical coherence tomography. Prog Retin Eye Res. 2018; 66: 132-56. http:// doi.org/10.1016/j.preteyeres.2018.04.002.

4. de Carlo TE, Romano A, Waheed NK et al. A review of optical coherence tomography angiography (OCTA). Int J Retina Vitreous. 2015. http://doi.org/10.1186/s40942-015-0.

5. Huang D, Jia Y, Gao SS, Lumbroso B et al. Optical Coherence Tomography Angiography Using the Optovue Device. Dev Ophthalmol. 2016; 56: 6-12. https://doi.org/10.1159/000442770.

6. Ang M, Tan ACS, Cheung ChMG et al. Optical coherence tomography angiography: a review of current and future clinical applications. Graefes Arch Clin Exp Ophthalmol. 2018; 256(2): 237-45. https://doi.org/10.1007/s00417-017-3896-2.

7. Spaide RF, Fujimoto JG, Waheed NK et al. Optical coherence tomography angiography. Prog Retin Eye Res. 2018; 64: 1-55. http://doi.org/ 10.1016/j.preteyeres.2017.11.003.

8. Werner AC, Shen LQ. A Review of OCT Angiography in Glaucoma. Semin Ophthalmol. 2019; 34(4): 279-286. https://doi.org/10.1080/08 820538.2019.1620807

9. Chalam KV, Sambhav K. Optical Coherence Tomography Angiography in Retinal Diseases. J Ophthalmic Vis Res. 2016; 11(1): 84-92. https://doi.org/10.4103/2008-322X.

10. Rolle T, Dallorto L, Tavassoli M et al. Diagnostic Ability and Discriminant Values of OCT-Angiography Parameters in Early Glaucoma Diagnosis. Ophthalmic Res. 2019; 61(3): 143-52. https://doi.org/10.1159/000489457.

\section{Authors' contributions:}

Katarzyna Paczwa 40\%; Justyna Mędrzycka 40\%; Joanna Gołębiewska 10\%;

Radosław Różycki 10\%.

Conflict of interest:

None.

Financial support:

None.

Ethics:

The content presented in the article complies with the principles of the Helsinki

Declaration, EU directives and harmonized requirements for biomedical journals. 